\title{
O MÉTODO DELPHI E A VALIDAÇÃO DE PESQUISA NA EDUCAÇÃO: UM ESTUDO COM PROFESSORES DE CIENCIAS DOS ANOS INICIAIS ATUANTES EM SALAS MULTISSERIADAS NA AMAZÔNIA
}

Silvana Ferreira Lima

Graduada em Licenciatura Plena em Pedagogia pela Universidade do Estado do Pará (UEPA). Mestranda em Educação em Ciências e Matemáticas na Universidade Federal do Pará (UFPA). E-mail: silvanaferreira.uepa@gmail.com

\section{Enilene da Conceição Nunes}

Ronilson Freitas de Souza

\begin{abstract}
Graduada do Curso de Licenciatura Plena em Pedagogia pela Universidade do Estado do Pará. Atualmente trabalha como professora na Escola Municipal de Ensino Fundamental de Cururú, localizada no espaço rural, vinculada a Secretaria de Educação de Salvaterra ( SEMED). E-mail:lenenunes17@gmail.com
\end{abstract}

Possui doutorado em Química Orgânica pelo PPGQ da Universidade Federal do Pará. Atualmente é professor do Departamento de Ciências Naturais da Universidade do Estado do Pará (UEPA). E-mail: ronilson.uepa@br.com

\section{RESUMO}

O presente artigo tem como objetivo demonstrar como o método Delphi e seus caminhares podem colaborar como instrumento de validação de pesquisa científica. Para esse estudo, utilizou-se a pesquisa de caráter qualitativo e como estratégia de coleta de dados fora utilizado um questionário semi-estruturado. A pesquisa se desenvolveu com professores de escolas públicas de Salvaterra, Marajó-PA, que atuam em salas/classes multisseriadas, o estudo se desenvolveu no mês de agosto no ano de 2018. Os resultados apontaram que esse método é uma forma viável de validar um instrumento de pesquisa uma vez que ao desenvolver do trabalho percebeu-se que algumas perguntas geraram ambiguidades aos sujeitos entrevistados, logo a tomada de decisão dos pesquisadores foi reelaborar as perguntas norteadoras do questionário para que $\mathrm{o}$ público-pesquisado, no momento final da pesquisa, tivesse a melhor compreensão das intenções de investigação do que se refere ao Ensino de Ciências da Natureza no ambiente multisseriado. 
PALAVRAS-CHAVE: Método Delphi. Ensino de Ciências da Natureza. Validação de Pesquisa.

\title{
THE DELPHI METHOD AND VALIDATION OF RESEARCH IN EDUCATION: A STUDY WITH SCIENCES TEACHERS FROM THE EARLY YEARS ACTING IN MULTISERIATED ROOMS IN THE AMAZON
}

\begin{abstract}
This article aims to demonstrate how the Delphi method and its paths can collaborate as an instrument for validating scientific research. For this study, qualitative research was used and a semi-structured questionnaire was used as a data collection strategy. The research was developed with teachers from public schools in Salvaterra, Marajó-PA, who work in multi-grade classrooms / classes, the study was developed in August in 2018. The results showed that this method is a viable way to validate a research instrument since when developing the work it was noticed that some questions generated ambiguities to the interviewed subjects, so the researchers' decision making was to rework the guiding questions of the questionnaire so that the researched public, at the final moment of the research, had better understanding of the research intentions regarding the Teaching of Natural Sciences in the multiseriate environment.
\end{abstract}

KEYWORDS: Delphi Method. Teaching of Natural Sciences. Research Validation.

\section{INTRODUÇÃO}

O presente estudo faz menção a um recorte do trabalho de conclusão de curso das autoras com enfoque ao Ensino de Ciências da Natureza dos anos iniciais e tem como objetivo compreender a realidade das escolas multisseriadas partindo do método Delphi que é um método preciso de validação de pesquisa. Para este artigo utilizou-se a aplicação de questionários.

O método Delphi possui passos e/ou orientações a serem seguidas pelos pesquisadores, segundo Azevedo (2019) o primeiro passo é a "escolha de um facilitador" que esteja fora do grupo de pesquisadores, o segundo é identificar seus especialistas, que nesse trabalho são os professores, o terceiro é a definição do problema a ser investigado, o quarto é a primeira rodada de perguntas, o quinto é a "segunda rodada de perguntas", o sexto é a terceira e ultima rodada de perguntas. Por fim, o sétimo passo e último do método, que é a tomada de decisão e o 
documento validado pelo pesquisador.

O método Delphi é um instrumento de pesquisa pouco utilizado no Brasil e pouco agregado na área da Educação. A eficácia desse método se consolida com o objetivo de permitir que o pesquisador faça uma avaliação de sua pesquisa estudando mais e intensamente seu objeto, pode-se entender melhor o propósito desse método com a seguinte citação:

Este método permite estudar, dentro do campo da educação, diferentes aspectos, como: criação e validação de instrumentos de coleta de dados; identificação de perfis profissionais; identificação de demandas, necessidades e tendências no campo educacional; e avaliação de cursos, currículos e sistemas avaliativos. É uma ferramenta valiosa para estudos de avaliação, de planejamento e de elaboração de políticas educacionais. Por certo, são dimensões fundamentais para o desenvolvimento da educação em qualquer nível, estrutura ou sociedade. (ANTUNES, 2014, p. 70)

O método Delphi além de apresentar a função de validar os dados permite que o pesquisador tenha mais familiaridade com o problema de pesquisa e com o público alvo, nesse trabalho possibilitou que os autores antecipassem a aplicação final do questionário para fazer parte da monografia, este fato ocorre também para evitar ambiguidades na formulação das perguntas, nesse sentido a aplicação dos questionários junto ao método Delphi foi direcionada aos professores de sala multisseriada dos anos iniciais.

Segundo Azevedo (2019) não é possível prever o futuro, mas a técnica Delphi pode ajudar a compreender a probabilidade e o impacto de eventos futuros. $\mathrm{Na}$ aplicação do questionário o objetivo é tentar minimizar o máximo de possibilidades que ocasione ambiguidades nas perguntas com o sujeito que será entrevistado no trabalho final, percebe-se que o método Delphi dá condições de que o pesquisador entenda o contexto de pesquisa e estudo com um olhar mais abrangente.

Este trabalho tem como abordagem a pesquisa qualitativa e também de campo, para Prodanov (2013) pesquisa de campo é aquela utilizada com o objetivo de conseguir informações e/ou conhecimentos acerca de um problema. Além de utilizar o método Delphi de pesquisa, para a coleta de dados foi elaborado um questionário semi estruturado com perguntas abertas. $\mathrm{O}$ público-alvo foram professores do município de Salvaterra-PA, Arquipélago do Marajó, o espaço de pesquisa foi o rural entre quilombolas, ribeirinhas e do campo totalizando onze professores. O período de execução da pesquisa foi no mês de agosto de 2018.

\section{DESENVOLVIMENTO}


O orientador da monografia foi escolhido como "Facilitador", o problema formulado é "como ocorre o ensino de ciências da natureza em salas multisseriadas nos anos iniciais?" e a validação dos questionários e a entrevista sobrevieram nos dias 05, 06, 07 (respectivamente as rodadas de perguntas) no mês de agosto 2018 nas escolas do espaço rural com apenas professores de salas multisseriadas das respectivas instituições que a Tabela 1 indica. Dos entrevistados, as formações eram Pedagogia, Geografia, Língua Portuguesa, Etno Desenvolvimento, Magistério e cursando PARFOR, todos atuando nas séries iniciais.

Tabela 1: Identificação de datas, escolas e número de professores que foram entrevistados.

\begin{tabular}{|l|l|c|}
\hline Data de Execução & \multicolumn{1}{|c|}{ Identificação } & $\mathbf{N}^{\mathbf{0}}$ de professores \\
\hline $05 / 06 / 2018$ & $\begin{array}{l}\text { Escola Municipal de Ensino } \\
\text { Fundamental e Quilombola de } \\
\text { Boa Vista. }\end{array}$ & 3 \\
\hline $05 / 06 / 2018$ & $\begin{array}{l}\text { Escola Municipal de Ensino } \\
\text { Quilombola de Thomaz } \\
\text { Carneiro. }\end{array}$ & 1 \\
\hline $05 / 06 / 2018$ & $\begin{array}{l}\text { Escola Municipal de Ensino } \\
\text { Fundamental e Quilombola de } \\
\text { Barro Alto. }\end{array}$ & 2 \\
\hline $06 / 06 / 2018$ & $\begin{array}{l}\text { Escola Municipal de Ensino } \\
\text { Fundamental de Pingo D’água. }\end{array}$ & 1 \\
\hline $07 / 06 / 2018$ & $\begin{array}{l}\text { Escola Municipal de Ensino } \\
\text { Fundamental de Chiquita. }\end{array}$ & 1 \\
\hline & $\begin{array}{l}\text { Escola Municipal de Ensino } \\
\text { Fundamental de Mãe de Deus }\end{array}$ & 2 \\
\hline & $\begin{array}{l}\text { Fundamental de Vila Ceará } \\
07 / 06 / 2018\end{array}$ & 1 \\
\hline
\end{tabular}

Fonte: Dos Autores, 2018.

A discussão nessa sessão trás algumas entrevistas que os questionários suscitaram na pesquisa partindo da ótica dos autores. 
1. Quais as principais dificuldades você encontra para ensinar Ciências em sala multisseriada?

Resposta: Nas entrevistas foi possível notar que os pesquisadores entenderam o sentido da pergunta e que mais se acentuava como dificuldade é a organização de espaço e trabalhar com séries diversificadas.

\section{Como se dá o processo de planejamento e avaliação em Ciências numa sala multisseriada?}

Resposta: Nas entrevistas foi possível notar que os pesquisadores entenderam o sentido da pergunta e a maior parte dos professores acentuam que é da mesma forma que se planeja as outras disciplinas, também citaram a reunião no inicio de ano letivo com a SEMED, outros apontaram que é de forma interdisciplinar.

3. Em sua opinião a quantidade de aulas semanais é o suficiente para os alunos compreenderem determinadas unidades temáticas de Ciências?

Resposta: Nas entrevistas foi possível notar que os pesquisadores entenderam o sentido da pergunta. Dos entrevistados metade disseram que sim a outra disseram que não é suficiente para que os alunos compreendam o que o professor propõe como conteúdo, apontando que o foco de sala de aula é mais português e matemática e o tempo ficara reduzido para os outros componentes.

\section{Você propõe atividades extraescolares?}

Resposta: Nas entrevistas foi possível notar que os pesquisadores entenderam o sentido da pergunta e todos disseram que sim, às vezes caminham fora da escola para compreender algum conteúdo, pequenas amostras e também quando tem oportunidade em feiras escolares de escolas próximas da comunidade.

\section{Quais os maiores desafios encontrados nas atividades práticas em Ciências?}

Resposta: Nas entrevistas foi possível notar que os pesquisadores entenderam o sentido da pergunta e dos entrevistados citaram a falta de recursos didáticos na escola, também a falta de computador com acesso a internet.

\section{Em suas aulas de Ciências você faz referência com cotidiano dos alunos (casa, escola e bairro)?}

Resposta: Nas entrevistas foi possível notar que os pesquisadores entenderam o sentido da pergunta e todos sem delongas responderam que sim.

\section{Você cria oportunidade de interação dos alunos com a Natureza?}


Resposta: Nas entrevistas foi possível notar que os pesquisadores entenderam o sentido da pergunta e responderam que sim, inclusive um dos professores citou que teve dificuldade em trabalhar seres vivos e não vivos com os alunos então levou materiais para sala e teve êxito com atividade.

\section{Como ocorre a interdisciplinaridade nas aulas de Ciências?}

Resposta: Essa pergunta foi adaptada, as respostas obtidas foram mais no sentido de fazer menção da realidade dos alunos com o conhecimento do que com a interdisciplinaridade entre as ciências.

\section{Quais metodologias você utiliza durante suas aulas de Ciências?}

Resposta: Essa pergunta foi adaptada, pois os entrevistados confundiam com materiais pedagógicos, no caso criaram-se opções para que os entrevistados pudessem acentuar suas opções.

\section{Como você avalia os conhecimentos prévios dos alunos}

Resposta: Nas entrevistas foi possível notar que os pesquisadores entenderam o sentido da pergunta. E a resposta mais acentuada foi o método de provas e envolvimento dos alunos com a aula.

Portanto, após a ultima rodada de perguntas, a tomada de decisão fez com que reformulássemos duas das perguntas do questionário inicial, pois geravam duplo sentido quando direcionada aos professores e isso poderia causar um resultado negativo ou não descartável em nossa pesquisa caso uma pergunta chegasse a ser anulada.

A aplicação do método Delphi, além de nos possibilitar esses resultados dos questionários possibilitou os autores entender mais a organicidade dos espaços de salas multisseriadas, com o contato com esses ambientes percebemos que existem profissionais que atuam sozinhos em escolas com os alunos, em momentos eram professores, outros merendeiros, outras corpo técnico, enfim questões particulares de escolas do campo. Além do mais, as condições das escolas na maioria são precárias e o trabalho docente está nesse emaranhado de situações corriqueiras.

\section{CONSIDERAÇÕES FINAIS}

Portanto, esse artigo teve como objetivo demonstrar como o método Delphi e seus passos podem colaborar como instrumento de validação de pesquisa científica, nesse contexto, com o questionário. Essa técnica evitou que no questionário final houvesse uma ambiguidade nas 
O Método Delphi e a Validação de

respostas do público-alvo, no caso os professores de séries inicias atuantes de salas multisseriada. Além disso, os pesquisadores indo a campo também conseguiram ter uma visão mais ampla do campo da pesquisa e das problemáticas pertinentes no lócus pesquisado.

\section{REFERÊNCIAS BIBLIOGRÁFICAS}

ANTUNES, M. M. Técnica Delphi: metodologia para pesquisas em educação no Brasil. Rev. educ. PUCCamp., Campinas, v. 19, n. 1, p. 63-71, jan./abr. 2014.

AZEVEDO, J. S. F de. Técnica Delphi um Guia Passo a Passo. Disponível em: $<$ http://livrozilla.com/doc/1120843/t \%C3\%A9cnica-delphi-um-guia-passo- a-passo. Acesso em 14 de setembro de 2019. Adaptado de Haughey Duncan, PMP, em www.projectsmart.co.uk.

PRODANOV, C. C. Metodologia do trabalho científico: métodos e técnicas da pesquisa e do trabalho acadêmico. 2. ed. - Novo Hamburgo: Feevale, 2013.

LIMA, S. F., NUNES, E. C., SOUZA, R. F. O Método Delphi e a Validação de Pesquisa na Educação: Um Estudo com Professores de Ciências dos Anos Iniciais Atuantes em Salas Multisseriadas na Amazônia. Complexitas - Rev. Fil. Tem. Belém, v. 4, n. 2, p. 50-56, jul./dec. 2019. Disponível em: http://www.periodicos.ufpa.br/index.php/complexitas/article/view/8165>. Acesso em: 30 de janeiro de 2020. 